\title{
Astronomical aspects of Kreisgrabenanlagen (Neolithic circular ditch systems)- an interdisciplinary approach
}

\author{
Georg Zotti ${ }^{1}$ and Wolfgang Neubauer ${ }^{2}$ \\ ${ }^{1}$ VIAS-Vienna Institute for Archaeological Science, \\ University of Vienna, Franz Klein-Gasse 1/III, A-1190 Vienna, Austria \\ email: Georg.Zotti@univie.ac.at \\ ${ }^{2}$ Ludwig Boltzmann Institute for Archaeological Prospection and Virtual Archaeology, \\ Hohe Warte 38, A-1190 Vienna, Austria \\ email: Wolfgang.Neubauer@archpro.lbg.ac.at
}

\begin{abstract}
Since the 1980s, the entrances of a certain form of monumental Neolithic enclosure (Kreisgrabenanlage, KGA) have been discussed in relation to solstice or lunistice directions. In our current project we analyze astronomical orientations in more than 30 KGAs in Lower Austria, and combine virtual reconstructions based on previous magnetic surveys with horizon surveys and astronomical simulation software.
\end{abstract}

Keywords. Kreisgrabenanlage, Neolithic circular ditch system, astronomical alignments, virtual archaeology

\section{Introduction}

In recent decades, a certain class of archaeological structure has been identified from aerial photography and investigated by magnetic prospection and partial excavation: the Kreisgrabenanlage (KGA, Neolithic circular ditch system). These large structures, dating to about 4850/4800-4550/4500 B.C., are found in a large region of Central Europe extending over today's Hungary, Slovakia, Czech Republic, Austria, Germany and Poland, and involving several cultural groups previously identified by archaeological work (Fig. 1). They typically consisted of up to four concentric V-shaped circular ditches 45$180 \mathrm{~m}$ in diameter, up to four internal wooden palisade walls and at least two opposing, and sometimes up to five, entrances.

They were an integral but separated part of the associated Middle Neolithic settlements indicating a central-place role with no obvious defensive function. The current archaeological interpretation is that they were used as a multi-purpose cult place. They are the oldest known monumental buildings in Europe.

Nothing remains visible in today's landscape except for soil and crop marks in the areas currently in use for agriculture, which will likely destroy these structures in the next few decades. Currently about 135 such KGAs are known in Europe, about a third of which are located in Lower Austria north of Vienna.

\subsection{Astronomical aspects of $K G A s$}

Since the 1980s, the orientations of KGA entrances as seen from their centres have been reported to be connected with sunrise or sunset positions at the solstices or equinoxes (Becker 1996, Iwaniszewski 1996). On the other hand, KGAs in Slovakia have been related to lunistice azimuths, when observed not from their (unmarked) centres, but using 


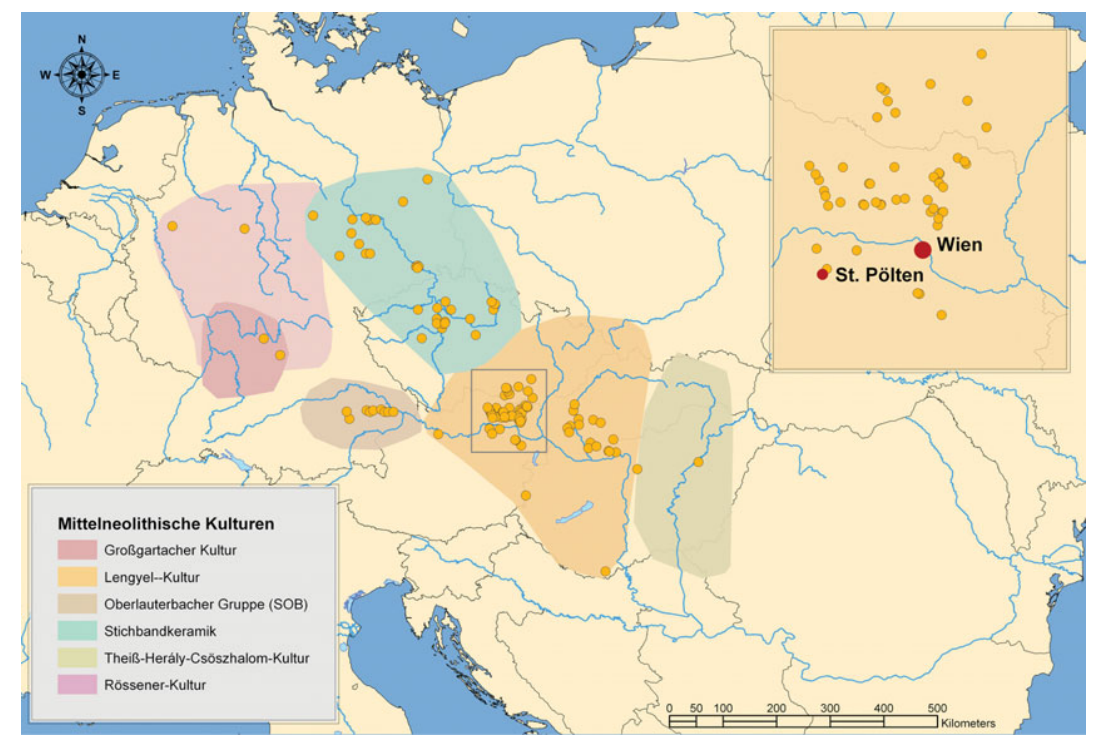

Figure 1. Distribution of known Kreisgrabenanlagen in Europe and their cultural groups.

sightlines between the entrances (Pavúk \& Karlovský 2004). A problem with central observations is the fact that the geometrical centre is frequently free from archaeological structures that could indicate a backsight; furthermore, at sites with more than one ditch or palisade, the sightlines formed by entrance pathways often do not intersect in the centre. At those sites, the pathways are usually taken to be the intended viewing directions (Zotti 2005, Pásztor 2008).

In 2003-04, Zotti undertook a first short overview study of the entrance orientation of 28 KGAs in Lower Austria combining KGA interpretation maps based on magnetic surveys and (for several sites) horizon information created from digital elevation models with a diagram showing solstice and lunistice curves and the diurnal tracks of brighter stars. In addition to confirming the solar orientation of several KGAs, for about one third of the KGAs a summary histogram indicated connections with a few selected stellar objects, most notably sightlines towards (1) the rising of the Pleiades in a direction almost opposite the (2) setting of Antares at a moment when (3) Deneb (the only brighter star then crossing the horizon in directions north of the major lunar standstill) reached its culmination - the latter star's rising and setting also being indicated. Zotti also argued that the observation of these risings (esp. heliacal) and settings could be understood as an early form of calendar keeping, maybe in connection with agricultural or livestock breeding activities. However, several directions of entrance orientations had to be left unexplained, with everything requiring confirmation by better surveys (Zotti 2005, 2008, 2010).

\section{New surveys, reconstruction and analysis}

In our ongoing interdisciplinary project we are trying to answer in more detail questions that had to be left open in the earlier study. The magnetic prospection results for the Austrian KGAs have been published in the meantime (Melichar \& Neubauer 2010). These data can now be accessed and evaluated with respect to the possible astronomical relationships of the KGAs.

An essential part of the project is site visits and accurate surveys of the landscape horizon, taken with a total station. In addition to the surveyed skyline, a series of photographs 
is taken which are then combined into a calibrated seamless panorama, providing a visual clue about near and far horizons, intersecting horizon lines which may be significant, or hints on vegetation and its effect on horizon altitudes. It is especially important to take these elevated horizons into consideration at sites on the floor of the Kamp valley, where we found horizon altitudes of more than $15^{\circ}$.

This horizon line and photograph is combined with an astronomical diagram showing declinations and, for the assumed period in time, the diurnal tracks of the sun at the solstices, equinoxes and cross-quarter days (i.e. where the solar ecliptic longitude $\lambda_{\odot}=$ $45^{\circ}+k .90^{\circ}, k \in[0,1,2,3]$ ), of the moon at the 4 lunar standstill declinations (showing also the slight differences of lunar topocentric parallax due to its elliptic orbit), and of the brighter stars. All of these take account of refraction and extinction: for stars, extinction angles for several atmospheric conditions can be seen, following Schaefer (1986).

These combined diagrams can be used to identify in an instant possible celestial and also terrestrial targets at any given azimuth on the horizon, and can also be used both as landscape background in astronomically enhanced virtual reconstructions, where they are mapped onto a spherical geometry always attached to the eye position so as to avoid parallax shift, and as foreground in 'desktop planetarium' programs.

The first visit to a KGA site in the real landscape during the project (Altruppersdorf, Fig. 2) motivated us to investigate in addition the potential of conspicuous landscape features such as isolated mountains and their use for marking specific dates as a possible motivation for selecting the site in question to build a KGA.

We cannot directly survey any surface features of KGAs, simply because there are none left. However, based on the magnetic prospection and excavation results (where available) we can create virtual reconstructions of the KGAs in a digital elevation model. Of course, given that only filled ditches and postholes remain, such virtual reconstructions of building structures are almost certainly incomplete, and depend upon current assumptions of how the KGA were used and present-day notions of how we would build such a structure with tools such as stone axes and antler picks. Nonetheless, reconstructing vertical palisade walls in the detectable traces of narrow trenches allows us to visualise, in the virtual environment, the approximate appearance of the KGAs.

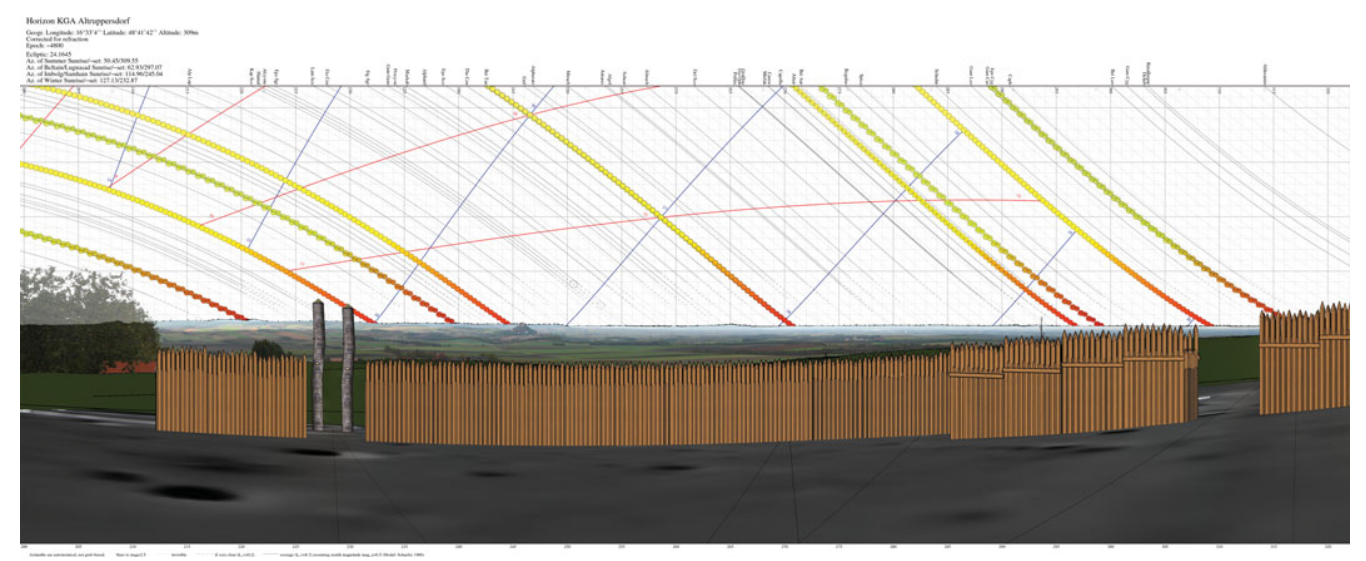

Figure 2. Part of the horizon at the Altruppersdorf KGA, combined with the astronomical evaluation diagram. Staatzer Berg, a pointed hill, is visible close to winter cross-quarter sunset. The palisade in the lower part (reconstructed here with $3.5 \mathrm{~m}$ height) was probably not high enough to cover the natural horizon. The lower entrance, which was marked by larger posts, clearly misses winter solstice as seen from here, the spot of a magnetic anomaly next to the geometrical centre. However, the north-western entrance (right) fits the summer solstice sunset. 


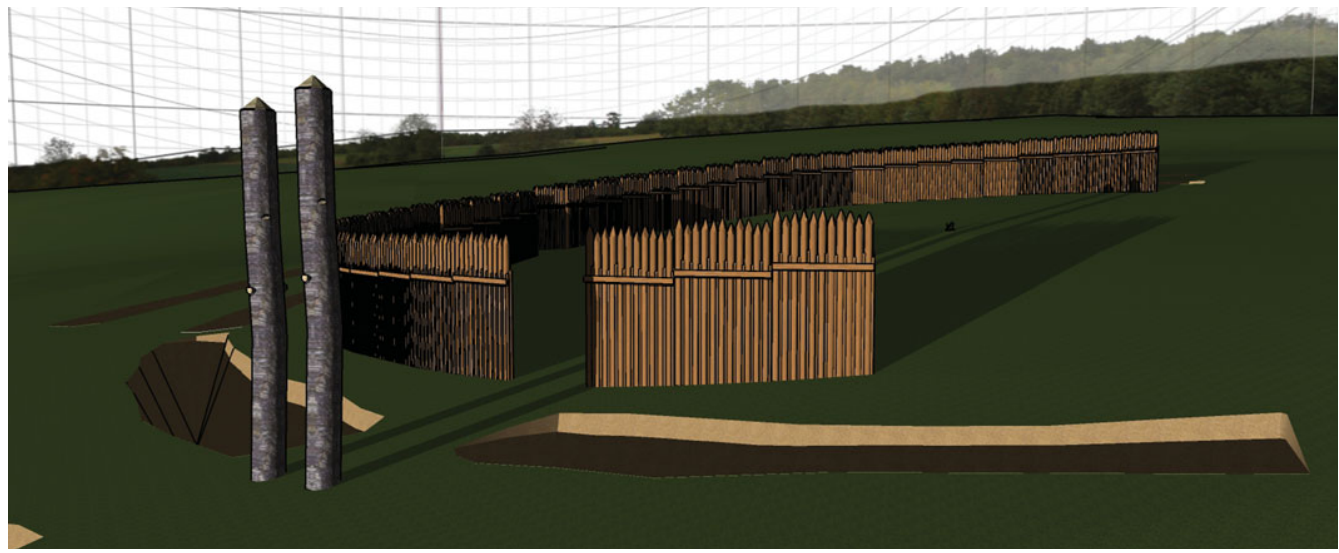

Figure 3. The Altruppersdorf KGA. The larger posts at the lower entrance cast shadows at winter solstice sunset that reach into the centre region. A tree trunk has been placed onto a magnetic anomaly which might have indicated a central post. However, the shadows of the setting sun continue a few metres further to the right before the sun actually sets.

Apart from the ditches, the magnetograms show anomalies (dark spots) which could be contemporary postholes, but may just as plausibly be from other periods. Their potential astronomical significance, if any, can be explored interactively in our astronomically enhanced virtual reconstructions when the ground is textured with the magnetogram. Of course, the photographic panorama is strictly valid only from a single viewpoint, but if the horizon is reasonably far away, any shift should be negligibly small.

The virtual reconstructions can be used additionally to study shadow phenomena, such as the first or last rays of sunshine being cast through the entrances into the central place on certain days (Fig. 3).

From the virtual models it is possible to create artificial panoramas of the palisades which can be combined with the photographic panorama and diagram, again to be directly evaluated or used with desktop planetarium software to show the sky from selected viewpoints.

The final step, currently under development, will be to permit a virtual walk through the KGAs in their landscape combined with a visually appealing sky simulation. Virtual reconstructions of this kind also help in communicating current archaeological opinions to a broader audience.

\section{Initial results}

\subsection{Lessons learned}

First and foremost, we must affirm that site visits by the astronomer remain essential for the understanding of an archaeological site in its landscape. Any 'desktop analysis' based on archaeological publications, including our 2003-04 study, is insufficient. Even horizon altitudes gained from digital elevation models can be somewhat in error, as can be seen when comparing the horizon in the previous virtual reconstructions with the measured and aligned horizon panoramas.

Typical archaeological publications present flat maps of archaeological features without any elevation information (e.g. Pavúk \& Karlovský 2004, Trnka 2005). Such flat maps suggest flat terrain, and encourage the view that the palisade always formed the skylinea sort of artificial horizon with the entrances as 'notches' indicating significant directions. 
The outside world in other directions is excluded from further consideration. From such maps, the astronomer is expected to read the azimuths and draw conclusions. While this may work in some cases, and does at least allow us to identify 'candidate directions' for astronomical orientation, it has become clear that, in general, much more data is necessary in cases where large archaeological structures like KGAs are placed in sloping terrain. Actually, we have to investigate three-dimensional structures situated in a threedimensional landscape.

From the on-site visits, combined with improved knowledge of the local topography, it has become clear that not all KGA entrances can be expected to have been astronomically motivated. Many entrances are much more easily explicable as simply leading up or down the sloping terrain, a view already expressed by Nikitsch (see Trnka 1991: 304f). The clearest example so far is Gauderndorf, whose south-eastern and north-western entrances are clearly outside even the lunar range, making stellar orientation the only astronomical possibility. On the other hand, the considerable slope of this site practically coincides with the direct line between the entrances, favouring this more down-to-earth explanation. At several sites, however, the entrance orientations are consistent with both astronomical and slope explanations, making it difficult to decide on the true intention of the constructors. It could even be suggested that this fact - the orientation of the slope towards (for example) a solstice - could have been one criterion in selecting a location to build a KGA.

The virtual reconstructions embedded in the landscape allow us to investigate and demonstrate another related aspect: even with a palisade several metres high, it is sometimes possible (where the terrain is steep enough) for an observer standing near the KGA centre and looking down the slope to see the valley floor or opposite slope behind the palisade edge. This runs counter to the common conception of KGAs as providing a closed space with the palisade walls preventing views into, or out of, the enclosures. In the case of Gauderndorf, any central observer would have seen ground, not sky, over the palisade edge on the south-eastern side. So, definitely not all KGAs could have been used for observational or calendrical purposes in the way previously suggested. The recently published report on the Austrian KGAs (Melichar \& Neubauer 2010) includes elevation information in the maps, allowing us to identify such slope-oriented entrances.

At many sites, erosion means that any trace of palisades has been lost. Even if they are partially visible, the exact location and width of the entrances is often hard to determine. Some of the reconstructions therefore show wide entrances and only partial palisades. Frequently more than one astronomically significant azimuth lies within such a wide gap, and it is impossible to say which was the more probable target (e.g., Fig. 4). We hope that the final results from more than 30 KGAs will permit a clearer conclusion.

\subsection{Examples}

\subsubsection{Altruppersdorf}

The only KGA that provides a conspicuous landscape feature possibly related to the observation of important solar or lunar events is Altruppersdorf. Only the western half is preserved, but this shows that there was no entrance oriented towards this pointed hill, Staatzer Berg. However, the slope is steep enough that the hill would have been visible over the palisade edge for a central observer, if the paliade was no higher than about 4.5m (Fig. 2).

The two entrances still detectable may, however, have been solstitially oriented. According to the magnetic survey (Melichar \& Neubauer 2010: 115), the lower, south-western entrance (the one to the left of Staatzer Berg) seems to have been accentuated by two strong, maybe taller, posts. This entrance is close to the downhill direction, so the stretch 


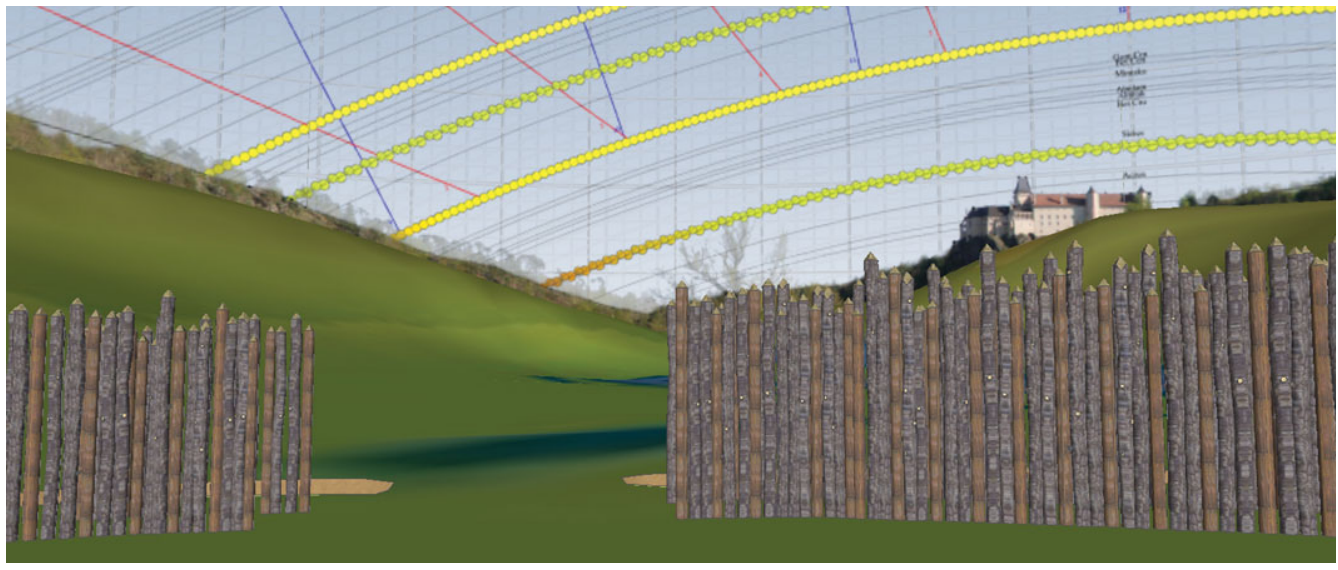

Figure 4. The lower entrance at the Rosenburg KGA. The horizon is lifted by the mountains to about 7 degrees, showing the necessity of horizon altitude measurements. The virtual reconstruction is combined with the photographic panorama of today's landscape, including the nearby castle. The width of the entrance is unclear, admitting both the winter solstice and major southern lunar standstill as possible orientation targets.

of horizon here was probably visible above the palisade edge. The tips of the double posts' shadows may have reached the centre region of the KGA around winter solstice sunset, so they may have been an appliance to project a shadow of solstitial sunset from the 'winter solstice' entrance to the centre, to permit its observation even though the palisade entrance was below the natural horizon line (Fig. 3). The other entrance, oriented towards the north-west, is closely aligned upon summer solstice sunset, again suggesting an intentional orientation.

A magnetic anomaly may indicate a central posthole close to the best-fit geometrical centre of the extant western half of the inner ditch ring, which is $55 \mathrm{~m}$ in diameter. However, the best-fit location for observing both solstices (through the twin posts and north-west entrance, respectively) is about $2-3 \mathrm{~m}$ away from this central anomaly, leaving some doubt about the 'true' observer location, especially for the winter solstice.

\subsubsection{Pranhartsberg 2: solstitial sightlines?}

The Pranhartsberg 2 KGA (Fig. 5) has two ditches and one palisade. Its entrances are accentuated by pathways between radial ditches. The axes of those pathways do not


Figure 5. Magnetogram and virtual reconstruction of the Pranhartsberg 2 KGA. The entrances are aligned towards winter solstice sunrise and summer solstice sunset. Two possible postholes in the north-western entrance are likewise aligned upon summer solstice sunset. 

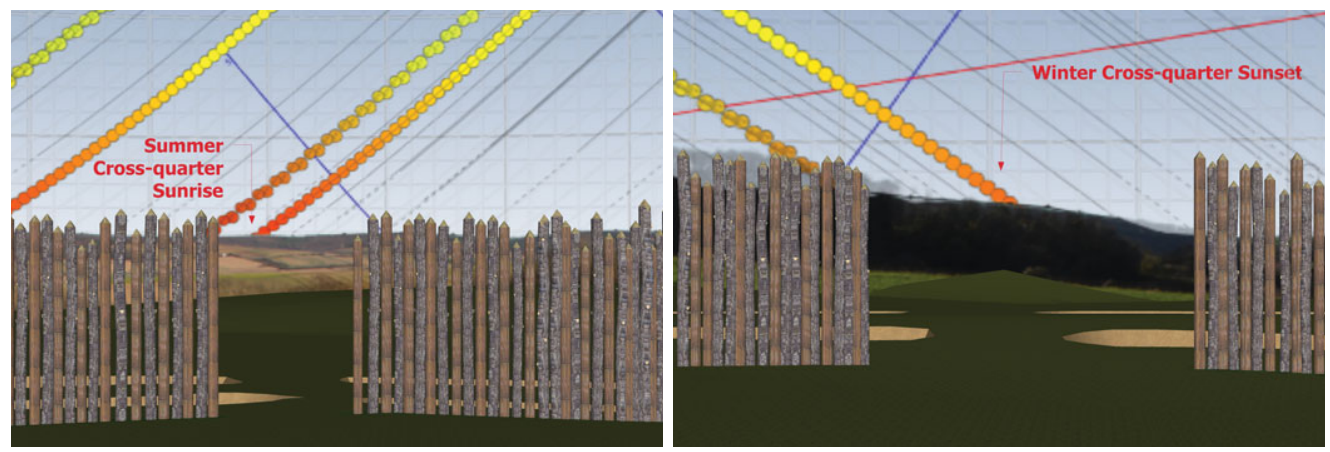

Figure 6. Puch KGA. Summer cross-quarter sunrise (left), and winter cross-quarter sunset over the elevated horizon (right), seen from the KGA centre.

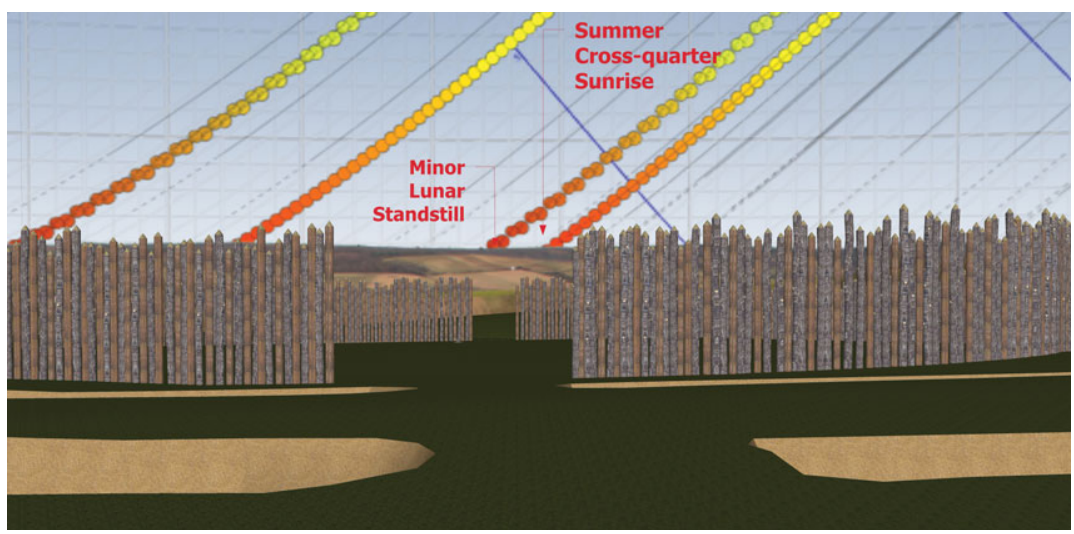

Figure 7. Puch KGA. The view through both entrances coincides with moonrise at minor standstill, but only in its azimuth. The palisade was probably not high enough to show the moon inside the entrance.

intersect at or near to the centre of the KGA, but the long pathways offer themselves as viewing directions towards winter solstice sunrise and summer solstice sunset.

In the magnetogram, two small anomalies, probably postholes, are visible in the northwestern entrance just where it crosses the main ditch. If we place posts in them, they provide a perfect alignment upon summer solstice sunset. However, the nature of the anomalies would require clarification by excavation.

\subsubsection{Puch: solar or lunar?}

An interesting case is Puch, a KGA with two ditches and one palisade. Seen from its geometrical centre, the two entrances are in perfect alignment with sunrise on the summer cross-quarter days (May/August) and sunset on the winter cross-quarter days (November/February). While the view to the north-east reaches over the valley to a horizon just $1^{\circ}$ high, the sunsets took place on a nearer horizon elevated to about $3^{\circ}$ (Fig. 6). The line connecting the entrances does not therefore cross the KGA's centre.

However, standing at the higher, south-western entrance and looking through both entrances, the azimuth of the other entrance coincides with the azimuth of northern minor lunar standstill.

This somewhat ambiguous result would support arguments for lunar orientation if the effect of the sloping terrain were neglected. As can be seen in Fig. 7, the opposing hill and landscape must have been visible over the edge of the palisade (unless it was more than 
$4 \mathrm{~m}$ high, which is unlikely given the depth of the palisade ditches). So at least it should not have been possible to observe the minor standstill moon framed by the entrance.

Opponents of astronomical orientation may note again that the two entrances are nearly, although not quite, aligned with the slope at the site.

\section{Conclusions and further work}

We cannot at this time give final percentages of solar, lunar or stellar orientations or probabilities of their intentional use. Some previous results seem to be confirmed, while others have to be reconsidered. Most notably, two factors have not been considered in earlier reports of astronomical orientations. These are the apparently frequent coorientation of the entrances with the slope of the local terrain, and the influence of this slope on the visibility of the natural horizon behind the palisades.

Many more virtual reconstructions, and the astronomical walk-through software, are still awaiting completion, and we hope to have a clearer view later in 2011.

\section{Acknowledgements}

This project is funded by the Austrian Science Fund (FWF P21208-G19, Project ASTROSIM).

\section{References}

Becker, H. 1996, Kultplätze, Sonnentempel und Kalenderbauten aus dem 5. Jahrtausend vor Chr. - Die mittelneolithischen Kreisanlagen in Niederbayern. Arbeitshefte des Bayrischen Landesamtes für Denkmalpflege, Nr. 59.

Iwaniszewski, S. 1996, Neolithic and Eneolithic structures in Central Europe: calendricastronomical implications. In W. Schlosser (ed.), Proceedings of the Second SEAC Conference, Bochum, Astronomisches Institut der Ruhr-Universität, Bochum, pp. 15-28.

Melichar, P. \& Neubauer, W. (eds) 2010, Mittelneolithische Kreisgrabenanlagen in Niederösterreich. Geophysikalisch-archäologische Prospektion-ein interdisziplinäres Forschungsprojekt, Verlag der Österr. Akad. d. Wissenschaften, Vienna.

Pavúk, J. \& Karlovský, V. 2004, Orientacia Rondelov Lengyelskej Kultury na Smery Vysokeho a Nizkeho Mesiaca (Orientation of Lengyel rondels to directions of High and Low Moon). Slovenská Archeológia 52(2), 211-280.

Pásztor, E. 2008, Megjegyzések a Lengyeli Kultúra Körárkainak Tájolásához (with German abstract: Bemerkungen zur Orientierung der Kreisgräbern der Lengyel-Kultur). Archaeologiai Értesitő 133, 5-20.

Schaefer, B. 1986, Atmospheric extinction effects on stellar alignments. Archaeoastronomy no. 10 (supp. J. Hist. Ast. 17), S32-S42.

Trnka, G. 1991, Studien zu mittelneolithischen Kreisgrabenanlagen, Verlag der Österr. Akad. d. Wissenschaften, Vienna.

Trnka, G. 2005, Katalog der mittelneolithischen Kreisgrabenanlagen. In F. Daim \& W. Neubauer (eds), Geheimnisvolle Kreisgräben-Niederösterreichische Landesausstellung 2005 (Exhibition Catalog), Verlag Berger, Horn \& Vienna, pp. 244-247.

Zotti, G. 2005, Kalenderbauten?-Zur astronomischen Ausrichtung der Kreisgrabenanlagen in Niederösterreich. In F. Daim \& W. Neubauer (eds), Geheimnisvolle KreisgräbenNiederösterreichische Landesausstellung 2005 (Exhibition Catalog), Verlag Berger, Horn \& Vienna, pp. 75-79.

Zotti, G. 2008, Zur astronomischen Interpretation ausgezeichneter Richtungen der Kreisgrabenanlagen Niederösterreichs. Acta Praehistorica et Archaeologica 40, 61-67.

Zotti, G. 2010, Astronomische Aspekte der Kreisgrabenanlagen in Niederösterreich. In: P. Melichar \& W. Neubauer (eds), Mittelneolithische Kreisgrabenanlagen in Niederösterreich. Geophysikalisch-archäologische Prospektion-ein interdisziplinäres Forschungsprojekt, Verlag der Österr. Akad. d. Wissenschaften, Vienna, pp. 136-167. 